\section{A variação linguística em materiais didáticos de língua portuguesa: ultrapassando as barreiras do erro}

Linguistic variation in didactic materials of portuguese: overcoming mistake restraints

Eleonora Figueiredo Correia Lucas de MORAIS (UECE) eleonora.lucas@aluno.uece.br Fernanda Rodrigues Ribeiro FREITAS (UECE) fernanda.posla@gmail.com Aluiza Alves de ARAÚJO (UECE) aluizazinha@hotmail.com Nukácia Meyre Silva ARAÚJO (UECE) nukacia.araujo@uece.br
MORAIS, Eleonora Figueiredo Correia Lucas de; FREITAS, Fernanda Rodrigues Ribeiro; ARAÚjO, Aluiza Alves de; ARAÚJO, Nukácia Meyre Silva. A variação linguística em materiais didáticos de língua portuguesa: ultrapassando as barreiras do erro. Entrepalavras, Fortaleza, v. 7, p. 475-489, ago./dez. 2017.

Resumo: Este trabalho tem como objetivo analisar materiais didáticos destinados ao ensino de Língua Portuguesa em relação à presença de conteúdos de Sociolinguística e à forma como esses conteúdos são abordados. Foram analisados dois materiais didáticos do tipo livro impressos e um objeto de aprendizagem (OA) do tipo vídeo. Este trabalho se baseia, principalmente, nos pressupostos da Sociolinguística Educacional, em que podemos destacar os trabalhos de Roncarati (2013) e de Cyranka (2009). Em relação à análise dos materiais didáticos, baseamo-nos em Soares (2002) e nos PCN (BRASIL, 1998). As principais conclusões a que chegamos a partir da análise dos materiais didáticos impressos é que, embora a presença do ensino de temas relacionados à Sociolinguística, especialmente no que se refere à oralidade, tenha evoluído muito, ainda carece de sistematização nos materiais didáticos impressos. Em relação ao vídeo analisado, percebese que a concepção de língua(gem) e, consequentemente, de ensino não está de acordo com as perspectivas mais atuais sobre o ensino de variação linguística.

Palavras-chave: Ensino de Língua Portuguesa. Variação linguística. Material didático. 
v. 7 (2)

475-489 ago/dez 2017

Abstract: This work aims to analyze didactic material destined to the teaching of Portuguese Language in what concerns to the presence of contents of Sociolinguistics and how these contents are approached. Two printed book type materials and one video learning object (OA) were analyzed. This work is based mainly on the assumptions of Educational Sociolinguistics, in which we can highlight the works of Roncarati (2013) and Cyranka (2009). Regarding the analysis of didactic materials, we are based on Soares (2002) and on PCN (BRASIL, 1998). The main conclusions we draw from the analysis of printed didactic materials is that, although the presence of the teaching of subjects related to sociolinguistics, especially according to orality, has evolved a lot, it still lacks systematization in printed didactic materials. In relation to the analyzed video, it is perceived that the conception of language and, consequently, of teaching is not in agreement with the most current perspectives on the teaching of linguistic variation.

Keywords: Teaching of Portuguese Language. Linguistic variation. Didactic material.

\section{Introdução}

O ensino de Língua Portuguesa é, há muito, objeto de discussão por parte dos teóricos da Linguística e da Educação. Parece haver um consenso no que diz respeito à necessidade de que o ensino da língua materna deve ser voltado para as práticas sociais, efetivadas por meio da linguagem, na qual os falantes da língua estão inseridos.

As discussões sobre as novas necessidades teórico-metodológicas em relação ao ensino de língua materna trouxeram avanços importantes em relação aos documentos oficiais que têm como função orientar a prática pedagógica na educação básica. Um dos temas mais importantes para a compreensão da língua em toda a sua complexidade é o da variação linguística, a respeito da qual os Parâmetros Curriculares Nacionais (PCN) e os Parâmetros Curriculares Nacionais para o Ensino Médio (PCNEM), por exemplo, trazem reflexões importantes.

Apesar disso, observam-se, nas salas de aula, ainda práticas pedagógicas voltadas para um ensino prescritivo da língua, não deixando de lado o ensino da variação linguística propriamente dita, mas não promovendo reflexões efetivas sobre o assunto. Característica semelhante é observada, também, nos materiais didáticos para o ensino de língua materna.

Nesse sentido, o principal objetivo deste trabalho é mostrar as relações não só importantes, mas necessárias, entre o ensino de Língua Portuguesa enquanto língua materna e a Sociolinguística. Com isso, pretendemos mostrar como o ensino da variação linguística, que, a nosso ver, é um dos principais conceitos da Sociolinguística que deve ser aplicado ao ensino, tem sido trabalhado não só na sala de aula, mas também nos próprios materiais didáticos. 
A principal inovação deste trabalho se dá em relação à consideração dos materiais didáticos digitais e da abordagem da Sociolinguística nesse tipo de material, o que, como foi observado em nossa pesquisa bibliográfica, não é um assunto muito abordado por pesquisadores da área. Analisamos dois livros impressos destinados ao $9^{\circ}$ ano do ensino fundamental e um objeto de aprendizagem (OA) em forma de vídeo disponível no Banco Internacional de Objetos Educacionais (BIOE).

Os livros impressos são "Para viver juntos: português $9^{0}$ ano", de Greta Marchetti, Heidi Strecker e Mirella L. Cleto e "Português: uma proposta para o letramento - $9^{\circ}$ ano", de Magda Soares. O vídeo é intitulado "Nossa Língua Portuguesa" do qual participam alguns professores de Língua Portuguesa cujo objetivo é discutir o uso da Língua Portuguesa em alguns contextos de interação.

Por questões metodológicas, optamos por analisar, de ambas as obras, a versão destinada ao professor, a fim de verificarmos a existência e a pertinência de orientações relativas ao trabalho com a oralidade e com a variação linguística e de que forma os autores se posicionam em relação à concepção de linguagem e o tipo de ensino adotados no material.

Este trabalho, que se insere no campo pressupostos da Sociolinguística Educacional, se inicia com uma breve explanação acerca da relação, a nosso ver, necessária entre os preceitos da Sociolinguística e o ensino de Língua Portuguesa como língua materna. Para isso, trazemos algumas pesquisas, como a de Roncarati (2008) e a de Cyranka (2009), que versam sobre esse assunto. Nesse contexto, outras pesquisas são, também, evocadas a fim de dar um maior suporte ao nosso estudo. Em seguida, procedemos à análise dos materiais didáticos analisados por nós e, por fim, tecemos algumas considerações finais acerca do tema.

\section{A sociolinguística e os materiais didáticos para o ensino de língua portuguesa}

Há muito se considera que os preceitos da Sociolinguística são importantes para o ensino de línguas, em especial para o ensino de língua materna no que se refere à oralidade, e muito se tem avançado nesse sentido. Há alguns anos, por exemplo, o ensino da oralidade na escola era omitido ou, quando não, era deturpado. Os próprios documentos oficiais trazem orientações metodológicas importantes nesse sentido, como se observa nos PCN de Língua Portuguesa, que destacam que 
v. 7 (2)

475-489 ago/dez 2017

Cabe à escola ensinar o aluno a utilizar a linguagem oral nas diversas situações comunicativas, especialmente nas mais formais [...]. Trata-se de propor situações didáticas nas quais essas atividades façam sentido de fato, pois seria descabido treinar o uso mais formal da fala. A aprendizagem de procedimentos mais eficazes tanto de fala como de escrita, em contextos mais formais, dificilmente ocorrerá se a escola não tomar para si a tarefa de promovê-la. (BRASIL, 1998 p. 27).

A esse respeito, Antunes (2003) aponta alguns problemas em relação ao ensino na oralidade: i) quase omissão da fala enquanto objeto de estudo na realidade escolar, prática esta que estaria ligada a uma possível consideração errônea de que a fala, enquanto parte inerente do cotidiano, não carecia de sistematização didática; ii) visão da fala como lugar da transgressão das regras gramaticais, possivelmente baseada na perspectiva dicotômica entre fala e escrita; iii) foco nos gêneros da oralidade informal, que, normalmente, eram trabalhados de forma intuitiva pelos alunos sem que houvesse uma análise mais aprofundada e consistente a respeito deles; iv) privilégio de convenções sociais do falar em público, em situações prestigiadas em detrimento dos outros gêneros orais, estigmatizados.

Há várias pesquisas que relacionam a Sociolinguística - em especial, a variação linguística - e o ensino de língua materna, dentre as quais podemos citar Roncarati (2008), que fala sobre o prestígio e o preconceito em contextos educacionais, que, no trabalho da autora, ultrapassam os muros da escola; Cyranka (2009) e Silva e Cyranka (2009), que falam sobre o estudo da variação linguística em contextos educacionais escolares, tratando das competências em relação uso de diversas variantes e sobre a valorização da tradição linguística. Winch (2013) e Scherre (2013), por sua vez, trazem à tona questões relativas a materiais didáticos de LP.

A primeira fala sobre o tratamento da diversidade linguística em materiais didáticos de LP, focando em três elementos principais dessa diversidade (alterações morfológicas, uso de expressões estrangeiras e sotaque), enquanto a segunda trabalha com o capítulo Escrever é diferente de falar do livro "Por uma vida melhor", aprovado pelo Ministério da Educação para a Educação de Jovens e Adultos. A autora busca discorrer sobre algumas questões relativas à divulgação do material, que, à época de sua publicação, causou uma série de críticas por parte de setores menos esclarecidos em relação à Linguística e ao ensino de línguas. 
Nesse sentido, é importante retornar ao fato de que os preceitos da Sociolinguística se fazem importantes especialmente para o ensino da oralidade. Reconhecemos a importância desses preceitos para o ensino da escrita, mas, por questões de delimitação metodológica, deter-nosemos nas questões relativas ao ensino da oralidade.

Com base nos trabalhos mencionados anteriormente e em material teórico sobre o ensino de língua materna, escolhemos dois materiais destinados ao $9^{\circ}$ ano do Ensino Fundamental para procedermos à análise de como são trabalhadas as questões relativas à oralidade e à variação linguística, podendo ou não estarem vinculadas entre si. Os materiais escolhidos para análise foram "Para viver juntos: português $9^{\circ}$ ano", de Greta Marchetti, Heidi Strecker e Mirella L. Cleto e "Português: uma proposta para o letramento - $9^{0}$ ano", de Magda Soares.

Em ambos os livros didáticos analisados por nós, os autores disponibilizam uma espécie de anexo ao final onde localizamos algumas considerações teóricas sobre a forma como o livro foi construído. Em ambas as obras, os autores afirmam trabalharem com a concepção sociointeracionista da linguagem. Soares (2002, p. 7) afirma que:

Assumindo esta concepção de língua, e pretendendo-se que o letramento, tal como foi anteriormente definido [estado ou condição de quem não só sabe ler e escrever, mas exerce as práticas sociais de leitura e de escrita], seja, nesta coleção, o fundamento e a finalidade do ensino do Português, esse ensino é aqui desenvolvido pela proposta de práticas de interação discursiva, por meio de textos orais (falar e ouvir) ou escritos (escrever e ler) de diferentes tipos e gêneros, dependendo das condições de produção do texto.

Com base no que a autora cita, acreditamos que uma questão importante de ser abordada no ensino de língua materna, em especial, quando se trata da perspectiva de letramento, é a da variação linguística, bem como da conscientização a respeito de variantes de prestígio e de variantes estigmatizadas. Da mesma forma, procedem os autores de "Para viver juntos: português $9^{0}$ ano". Na obra, os autores afirmam que:

[no livro], a linguagem verbal é compreendida como processo de interação que se realiza nas práticas sociais. Estas são múltiplas e apresentam características variadas, definidas pelo interlocutor colocado em cada uma das situações comunicativas, pelas finalidades que se pretendem atingir, pelas características do suporte no qual o discurso circulará e pelas especificidades do gênero no qual o discurso será organizado. (2012, p. 6. Grifo nosso) 
v. 7 (2)

475-489 ago/dez 2017

Quando se fala em uso de material didático digital (doravante MDD) na sala de aula, ou se fala do uso de ferramentas e aplicativos a que se tem acesso no ambiente digital, via internet, como recursos no ensino, ou se fala de Objetos de Aprendizagem (grosso modo, recursos de áudio, vídeo, animação/simulação, softwares pedagógicos, que apresentam fins didáticos e podem complementar a abordagem de conteúdos a serem ensinados-aprendidos).

No entanto, até o presente momento, pesquisas sobre como se compõem os MDDs para o ensino de Língua Portuguesa (doravante LP) ainda são escassas. Entre os poucos trabalhos sobre o assunto, é possível citar Megid (2013), em cujo trabalho se analisa, em uma perspectiva do discurso, a aplicação de Objetos de Aprendizagem em forma de vídeo no ensino de Língua Portuguesa. Além desse trabalho, existem também outras pesquisas que tratam da relação entre o uso de vídeos educacionais e o ensino de LP, entre elas estão Cabero-Almenara (1998), Ferrés (1998), Moran (2009).

A partir deste tópico, conduziremos uma discussão sobre MDD na perspectiva da abordagem da língua(gem), no que tange à variação linguística, em vídeo voltado para o ensino de Língua Portuguesa ${ }^{1}$, com base nas pesquisas desenvolvidas por Garcia (2014). Em função do espaço limitado para discussão, optamos por analisar apenas um Objeto de Aprendizagem (doravante $\mathrm{OA})^{2}$ de tipo vídeo, com foco no ensino de LP, presente no Banco Internacional de Objetos Educacionais (doravante BIOE) ${ }^{3}$.

Garcia (2014), inicialmente, fez um levantamento dos vídeos disponíveis no BIOE e encontrou, nesse repositório, 153 vídeos para ensino de Língua Portuguesa. Posteriormente, os dividiu entre vídeos que exploravam temas relacionados à literatura brasileira, ou a outros

\footnotetext{
${ }^{1}$ É importante ressaltar que, considerando o atual contexto de ensino e aprendizagem, de que fazem parte os jovens da geração internet, o uso de vídeos educacionais pode contribuir efetivamente para o processo de construção de conhecimentos, visto que esses jovens, desde seu nascimento, entram em contato, de diferentes formas, com imagens. Sendo assim, os vídeos, assim como outros recursos imagéticos, são parte da realidade comunicativa em que os alunos estão inseridos, seja no interior ou além dos limites da escola.

2 Os OAs, também conhecidos como Objetos Educacionais, têm muitas definições. Neste artigo, a concepção com a qual trabalharemos é a de Wiley (2000), que caracteriza OA como "qualquer recurso digital que possa ser reutilizado no apoio à aprendizagem".

3 O BIOE é um repositório, uma espécie de biblioteca virtual, cujo propósito é guardar, de forma organizada, o maior número possível de OAs para que o usuário possa encontrá-los mais facilmente (por série/segmentos de ensino, tipos, disciplinas, propósito educacional, por exemplo).
} 
assuntos que não tratassem especificamente de análise linguística, e vídeos que tratavam de língua(gem), considerando a separação que a escola faz entre "ensino de LP" e "ensino de literatura".

Após a primeira triagem, sobraram ainda 110 OAs de tipo vídeo: 57 do grupo "Nossa Língua Portuguesa", 36 do grupo "A Língua Portuguesa é Nossa" e 17 do grupo "Conexão Linguagem". Como afirmamos anteriormente, levando em consideração o recorte necessário devido ao escopo deste trabalho, escolhemos apenas um vídeo para análise, o qual faz parte do grupo "Nossa Língua Portuguesa". Esse vídeo será apresentado e analisado no próximo tópico.

\section{Análise dos materiais didáticos}

Neste tópico, procederemos à análise dos materiais didáticos que serviram de corpus para este trabalho. Para isso, iniciaremos discorrendo sobre os materiais didáticos impressos, a saber, "Para viver juntos: português $9^{\circ}$ ano", de Greta Marchetti, Heidi Strecker e Mirella L. Cleto e "Português: uma proposta para o letramento - $9^{\circ}$ ano", de Magda Soares. Posteriormente, discorreremos sobre a nossa análise dos MDDs, a saber um vídeo intitulado "Nossa Língua Portuguesa", como já foi mencionado anteriormente.

Nossa análise levou em consideração tanto aspectos didáticopedagógicos quanto à utilização, por parte dos autores, de elementos advindos da Sociolinguística, em especial, a questão da variação linguística, em que nos focamos para trabalhar com o nosso corpus.

Análise dos materiais didáticos impressos

O primeiro aspecto que consideramos importante de ser mencionado é a questão do próprio trabalho com a oralidade. Em ambas as obras, os autores procuram fazer um trabalho bastante sistematizado em relação ao estudo dos gêneros orais, o que é um ponto bastante positivo desses materiais, uma vez que o que se observa na maioria dos materiais didáticos destinados ao ensino de Língua Portuguesa como LM é que o trabalho com a oralidade é deixado de lado.

O motivo dessa quase desconsideração dos gêneros orais é, possivelmente, uma concepção dicotômica entre fala e escrita, que toma a fala como desorganizada e como sendo o lugar do "erro" e da falta de sistematização. Nesse sentido, ressaltamos que a disposição dos autores em trabalhar os gêneros orais em um livro didático, não deixando esse 
V. 7 (2)

$475-489$ ago/dez 2017

estudo somente a critério da escola que adotará o material, é bastante positivo.

Nesse ínterim, deve ser observada, além da existência desse trabalho com a oralidade, a forma como, efetivamente, essa questão é trabalhada. Na obra de Soares (2002), por exemplo, os gêneros orais são explorados em função dos gêneros escritos, de forma que os momentos em que os alunos são incentivados a se expressar oralmente são, normalmente, por meio de discussões ou de interpretações orais de algum gênero escrito.

Nota-se também que o trabalho com a variação linguística em relação à oralidade é preterido em relação à sistematização dos gêneros orais. Em todo o livro, que tem, em média, 200 páginas, há apenas duas - as páginas 74 e 75 - destinadas ao trabalho com a variação linguística. Na atividade em que, segundo a autora, serão estudadas as modalidades formal e informal da língua, observa-se que todas as atividades são pautadas pelo texto escrito, que, no capítulo em questão, é narrativo. Nela, a autora procura mostrar alguns registros informais que o autor do texto narrativo - escrito - faz em seu texto, como a troca do presente do subjuntivo pelo pretérito imperfeito do indicativo, bem como algumas questões de ordem vocabular e lexical.

Sabe-se que uma das questões basilares na teoria de Labov é a de que o estudo da língua deve se pautar por fatores que vão além dos internos à língua e incorporar elementos advindos da estrutura social em que o sistema linguístico se manifesta. Acreditamos que Soares (2002), ao trabalhar sob uma perspectiva de letramento em seu livro didático, já traz boas contribuições em relação à desconstrução de uma visão purista e essencialista da língua.

Entretanto, a autora deixa preterido o trabalho com a Sociolinguística e, em especial, com a questão da variação linguística, que, a nosso ver, é fundamental para o ensino efetivo da oralidade. Acreditamos que, dessa forma, o trabalho com a variação linguística ficou subaproveitado, uma vez que, como a autora traz uma série de discussões, debates e exposições orais, criaram-se diversas oportunidades para trazer à tona questões, como o prestígio e o preconceito linguísticos.

Ainda assim, observamos que, em um dos capítulos da segunda obra analisada - o capítulo 4 - os autores trazem um gênero que, apesar de fazer parte do cotidiano da maioria dos alunos, é bastante improvável que um dia eles precisem efetivamente utilizá-lo, que é a narração de partida de futebol. Desse modo, não há a consideração do 
uso social da linguagem, uma vez que, enquanto cidadãos comuns, não são narradores esportivos, é praticamente impossível que esse gênero textual faça parte das práticas sociais dos alunos.

Outro ponto a ser observado é o de que, apesar de os autores trabalharem com vários gêneros orais interessantes e que efetivamente fazem parte do conjunto de práticas sociais que os alunos desempenham ou que virão a desempenhar, ainda mais que no livro de Soares (2002), há uma desconsideração em relação aos fenômenos sociolinguísticos inerentes à oralidade. Não se consideram, por exemplo, elementos fonéticos ou fonológicos nem a questão da variação linguística ou sequer as questões de prestígio e de preconceito linguísticos.

Dessa forma, com base no que foi observado nos materiais didáticos impressos analisados, observou-se que as edições analisadas desconsideram quase que completamente as questões referentes à variação linguística, que, a nosso ver, são impreteríveis para um trabalho eficiente com o ensino de qualquer modalidade da língua e, em especial, com a modalidade oral.

Consideramos, portanto, que as obras do material didático impresso analisado por nós apresentam como uma grande vantagem em relação a diversas outras obras o fato de trabalharem com a oralidade de forma sistematizada e de fornecerem orientações didáticas bastantes, para que o trabalho com os gêneros orais seja bem-sucedido em sala de aula. Por outro lado, acreditamos que, para que esse trabalho seja efetivamente positivo e baseado nas práticas sociais em que os alunos estão inseridos, deveria haver a consideração de questões relativas à Sociolinguística, como variação linguística, prestígio e preconceito linguísticos, além de aspectos referentes à fonética e à fonologia, que poderiam aparecer para dar suporte aos outros aspectos supracitados.

Análise do material didático digital

Para proceder à análise do MDD, consideramos importantefazer uma breve contextualização acerca do corpus deste trabalho. No grupo "Nossa Língua Portuguesa", de autoria do Ministério de Educação, existiam, no período em que a pesquisa foi realizada, 57 vídeos disponíveis no BIOE, nos quais o professor Pasquale Cipro Neto ensinaria regras gramaticais e ortográficas durante e a partir de entrevistas com convidados. Esses vídeos, de modo geral, teriam como objetivo explicar o "uso correto" da Língua Portuguesa, levando em consideração os aspectos formais da língua. 
v. 7 (2)

475-489 ago/dez 2017

O vídeo escolhido para análise foi intitulado "Linguagem coloquial; particípio; presente do subjuntivo". De acordo com os metadados 4 , o objetivo desse OA seria "mostrar os principais "erros" cometidos na língua falada, a diferença entre a linguagem coloquial e a linguagem formal e a regra do particípio e do presente do subjuntivo".

Esse vídeo está dividido em duas partes: entrevista entre Pasquale e seus convidados5 e análise de letras de música ("Pra dizer adeus", dos Titãs; "Assim caminha a humanidade", de Lulu Santos e "O poeta está vivo", interpretada por Lobão). Sobre isso, Garcia (2014) afirma

que as duas situações são apresentadas de forma estanque, isto é, o professor interrompe a entrevista (várias vezes) e analisa as canções, que não se relacionam com os temas abordados na entrevista. Em outras palavras, não existe qualquer ligação entre as partes entremeadas do programa. Quebra-se o texto, interrompendo-se a entrevista, e apresentando-se a análise de letras de canções, que terminam por constituir o material linguístico de onde o apresentador retira "erros gramaticais". (GARCIA, 2014, p. 101)

O apresentador, no momento que antecede a análise das letras de música, entende que é preciso deixar claro que, de acordo com sua concepção de lingua(gem), "a língua falada é diferente da língua escrita, [pois] a língua escrita é formal, [enquanto] a língua falada é mais livre, mais solta, [nela] permitem-se coisas que na escrita não se permitem". Dito isso, analisa (na verdade, Pasquale condena) o uso recorrente de "pra" em vez da preposição "para" nas letras de "Pra dizer adeus" e "O poeta está vivo". De acordo com o apresentador do programa, usar "pra" na fala não estaria errado, já que se fala e se continuará "falando assim". No entanto, na escrita, considerando os aspectos formais que a subjazeriam, não se poderia utilizar essa expressão.

Já a análise da canção "Assim caminha a humanidade" é feita de forma diferente, já que, em vez de iniciar a discussão a partir da letra da música, o professor pede para que seja exibida uma entrevista curta realizada na rua com um jovem, na qual ele assume não saber

4 Os metadados são como etiquetas dos OAs que informam título, tipo do recurso, objetivo, descrição do recurso, observação, componente curricular, tema, autor(es), idioma, país, fonte do recurso, endereço eletrônico, data de publicação etc.

5 O grupo humorístico "Os sobrinhos do Ataíde", que é composto pelos integrantes Paulo Bonfá, Marco Bianchi e Felipe Xavier, os quais apresentam o quadro da rádio paulista 89FM "Superdicionário e Manual de Gramática Há Nível de Holanda". "Segundo os humoristas, na entrevista concedida ao apresentador, esse trabalho teria um viés humorístico e foi elaborado com uma proposta de análise dos principais "erros" que os falantes brasileiros cometem ao utilizarem a Língua Portuguesa." (GARCIA, 2014) 
se há alguma situação em que se possa fazer uso de "seje" (no lugar de "seja"). Após a apresentação do vídeo em que figura a entrevista, Pasquale discute situações em que se devem usar verbos no presente do subjuntivo. Nas figuras 1 e 2, podemos ver o momento do vídeo em que as explicações sobre as regras para se usar "corretamente" o tempo e o modo indicados são dadas.

Figura 1 - Regra para conjugar corretamente, no presente do subjuntivo, verbos terminados em -AR.

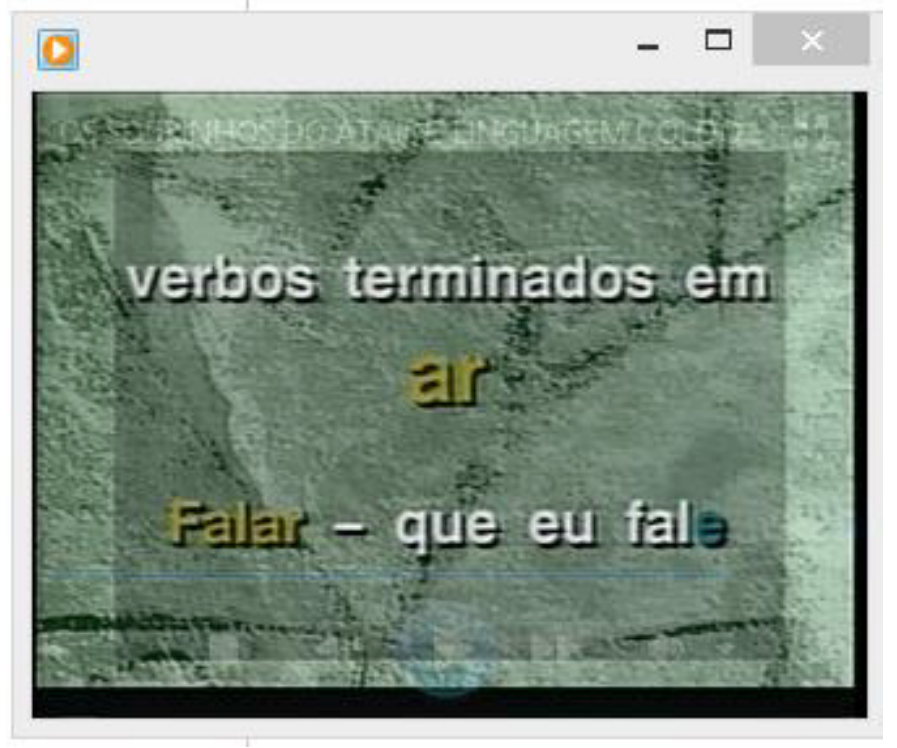

Figura 2 - Regra para conjugar corretamente, no presente do subjuntivo, verbos terminados em -ER e em -IR.

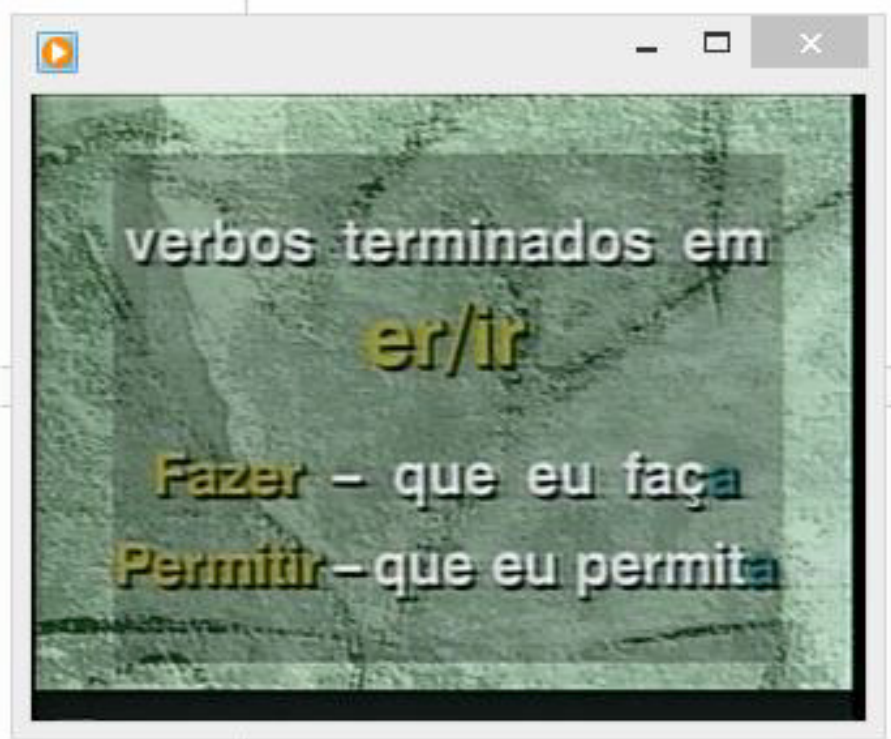


v. 7 (2)

475-489 ago/dez 2017

Após a explicação das regras, Pasquale apresenta o vídeo em que Lulu Santos canta um trecho de "Assim caminha a humanidade". O objetivo de apresentar esse vídeo parece ser o de ratificar o que foi explicado momentos antes de sua exibição. Vejamos, na figura abaixo, o momento em que o verbo "ser", conjugado na canção, estaria de acordo com a Gramática Normativa da Língua Portuguesa.

Figura 3 - Trecho da letra em que o presente do subjuntivo do verbo "ser" foi usado de acordo com a norma padrão.

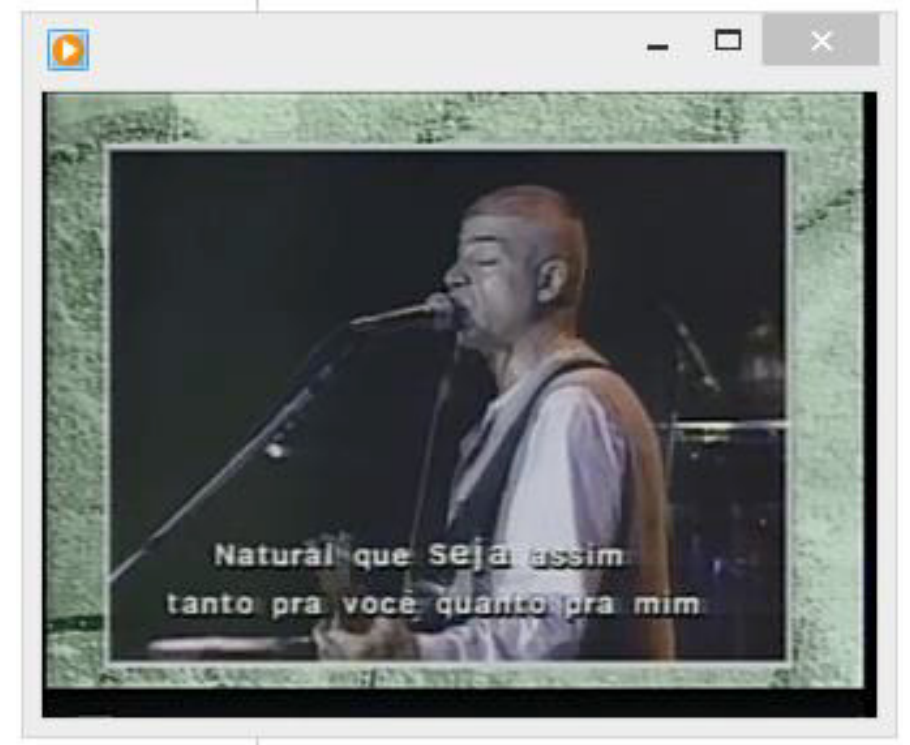

Após a apresentação do vídeo de Lulu Santos, o professor Pasquale faz uma observação (que diz respeito à exceção às regras discutidas no decorrer do programa). De acordo com ele, o verbo "estar" seria o único que não se encaixaria nessas regras, visto que, embora seja um verbo de primeira conjugação (terminado em - AR), a forma do verbo conjugada no presente do subjuntivo terminaria em " $A$ "6.

Tendo em vista o que foi exposto acerca do OA de tipo vídeo "Linguagem coloquial, particípio, presente do subjuntivo"; passemos à análise do tratamento do fenômeno de variação linguística nesse material didático digital.

De acordo com os Parâmetros Curriculares Nacionais da Língua Portuguesa (1998), não se pode mais insistir na ideia de que o modelo de correção estabelecido pela gramática tradicional seja o nível padrão de língua ou que corresponda à variedade linguística de prestígio. Há,

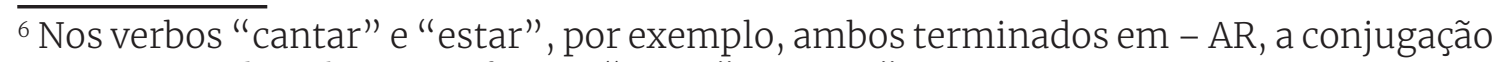
no presente do subjuntivo ficaria "cante" e esteja". 
isso sim, muito preconceito decorrente do valor atribuído às variedades padrão e ao estigma associado às variedades não padrão, consideradas inferiores ou erradas pela gramática (BRASIL, 1998, p.31)

Deve-se, portanto, considerar que a língua varia em diferentes contextos de uso e que exige uma linguagem que se adeque a cada contexto de enunciação, uma vez que a língua é heterogênea e que o fenômeno da variação linguística é inerente a todas as línguas. No entanto, no OA analisado, a perspectiva de língua(gem) que subjaz a ele reflete a desconsideração de fenômenos de variação linguística. Na concepção de Pasquale e de seus convidados, as variantes linguísticas são consideradas erradas, e, por isso, em nome do "bem falar" e do "bem escrever", deveriam ser rejeitadas. Sobre isso, Garcia (2014) completa

A postura (elitizada) do apresentador e de seus entrevistados revela, entre outros aspectos, uma concepção excludente em relação às camadas sociais populares, que supostamente possuem pouca escolarização e que, justamente por esse motivo, manifestam-se linguisticamente distanciadas das prescrições da gramática normativa. (GARCIA, 2014, p. 111)

Essa abordagem de ensino de LP se restringe ao que se pode ou não dizer/ escrever tendo como parâmetro a gramática tradicional. Desse modo, por ter como base a dicotomia certo/errado, essa concepção de língua(gem) aponta para uma abordagem de ensino-aprendizagem que privilegia um único uso da língua: a norma padrão. Assim, as variantes linguísticas são consideradas deformidades da língua, o que caracteriza o ensino como uma atividade mecanicista que ocorreria dentro de um sistema fechado, imutável.

Oensinodelínguas (maisespecificamenteodeLínguaPortuguesa), no entanto, deveria, assim como está descrito nas diretrizes, levar em consideração os aspectos sociais, culturais, históricos e ideológicos dos falantes, isto é, os elementos extralinguísticos que, em contextos reais de uso, colaboram para a compreensão dos eventos discursivos.

\section{Conclusão}

A partir do que discutimos neste artigo, podemos afirmar que cada vez mais se faz necessário o aporte da Sociolinguística na sala de aula. Esse aporte deve ser levado em consideração, especialmente, no que se refere à variação linguística, uma vez que é uma questão de grande relevância para o uso efetivo da linguagem nas diversas práticas sociais em que os alunos estão inseridos. 
v. 7 (2)

475-489 ago/dez 2017

É importante ressaltar que o trabalho com a oralidade nas salas de aula da educação básica já evoluiu muito, mas ainda carece de certa sistematização, inclusive no que refere aos materiais didáticos. Como foi observado nos livros impressos analisados neste trabalho, muito se trabalhou com a oralidade e pouco com a questão da variação linguística, que, a nosso ver, é essencial para o trabalho efetivo da oralidade.

Os MDDs, por sua vez, não podem ser considerados apenas como uma tendência no atual contexto de ensino-aprendizagem, pois já se efetivaram como uma realidade, visto que diretrizes, como os PCNs, têm destacado a relevância da disponibilização desses materiais multimídia, produzidos sob forma de jogos eletrônicos educativos, simuladores e infográficos animados, por exemplo, como complemento às atividades de sala de aula.

No entanto, uma questão deve ser observada: materiais didáticos digitais, assim como os impressos, devem apresentar qualidade teórica e didático-pedagógica, afinal, muitos desses materiais apresentam concepções de língua(gem) e de ensino que não costumam estar totalmente de acordo comas orientações das matrizes de referência, cujos objetivos apontam para novas abordagens e metodologias no tocante ao ensino, neste caso, de Língua Portuguesa.

Ao analisarmos o OA de tipo vídeo "Linguagem coloquial; particípio; presente do subjuntivo", concluímos que ele trata de LP a partir de uma perspectiva tradicional, prescritiva, que compreende a língua como um sistema, formado por formas inflexíveis. O conteúdo de ensino, nesse Objeto de Aprendizagem, é apresentado por meio de esquemas de memorização e de repetição da regra em si mesma, com base em frases artificializadas e descontextualizadas. Outro ponto que merece atenção é que, apesar de o OA analisado neste trabalho estar disponibilizado no Banco Internacional de Objetos Educacionais, o vídeo contraria as indicações de documentos publicados pelo próprio governo, a exemplo dos Parâmetros Curriculares Nacionais.

\section{Referências}

ANTUNES, I. Aula de português. São Paulo: Parábola Editoria, 2003.

BRASIL. Ministério de Educação. Secretaria de Educação a Distância. Banco Internacional de Objetos Educacionais. Disponível em: <https:// objetoseducacionais.mec.gov.br>. Acesso em: 15 de jun. de 2015.

BRASIL. Ministério da Educação. Secretaria de Educação Fundamental. Parâmetros Curriculares Nacionais: terceiro e quarto ciclos do ensino fundamental: língua portuguesa. 1998. Disponível em: <http://portal.mec. 
gov.br/seb/arquivos/pdf/portugues.pdf>. Acesso em: 11 dez. 2017.

CABERO-ALMENARA, J. Avaliar para melhorar: meios e materiais de ensino. In: SANCHO, J. M. (Org.). Para uma tecnologia educacional. Trad. Beatriz Affonso Neves. Porto Alegre: Artes Médicas, 1998.

CYRANKA, L. F. M. Uma perspectiva sociolinguística para o trabalho escolar com a língua materna. In: MIRANDA Sonia Regina; PACHECO, Luciana Marques. (org). Investigações: experiências de pesquisa em educação. Juiz de Fora: EDUFJF, 2009. p. 49-61.

FERRÉS, J. Pedagogia dos meios audiovisuais e pedagogia com os meios audiovisuais. In: SANCHO, Juana Maria (Org). Para uma tecnologia educacional. Trad. Beatriz Affonso Neves. Porto Alegre: Artes Médicas, 1998.

GARCIA, S. Análise de Objetos de Aprendizagem: a perspectiva de língua(gem) e de ensino em vídeos educacionais de Língua Portuguesa. 2014. Dissertação (Mestrado) - Universidade Estadual do Ceará, Fortaleza, 2014.

MARCHETTI, G.; STRECKER, H.; CLETO, M. L. Para viver juntos: português $9^{\circ}$ ano. São Paulo: Edições SM, 2012.

MEGID, M. C. Materiais didáticos audiovisuais e digitais no estudo de Língua

Portuguesa: deslocamento nas relações entre as posições-sujeito professor e aluno. [tese de doutorado]. Universidade Estadual de Campinas, Instituto de Estudos da Linguagem, Campinas - SP, 2013.

MORAN, J. M. Vídeos são instrumentos de comunicação e produção, mar, 2009. Entrevista concedida ao Portal do Professor / Ministério da Educação e Cultura. Disponível em: <http://portaldoprofessor.mec.gov.br/noticias.html>. Acesso em: 27 jan. 2014.

RONCARATI, C. Prestígio e preconceito linguísticos. In: Caderno de Letras da UFF. Rio de Janeiro. n. 36, 2008, p. 45-56.

SCHERRE, M. M. P. Verdadeiro respeito pela fala do outro: realidade possível? In: Revista Letra. Rio de Janeiro. v. 1, 2013, p. 51-62.

SILVA, V. S; CYRANKA, L. F. M. A Língua Portuguesa na escola ontem e hoje. In: Linhas Críticas. Brasília. v. 15, n. 29, 2009. p. 271-287.

SOARES, M. Português $\mathbf{9}^{\mathbf{0}}$ : uma proposta para o letramento. São Paulo: Moderna, 2002.

WILEY, D. A. Connecting learning objects to instructional design theory: A definition, a metaphor, and a taxonomy. In D. A. Wiley (Ed.), The Instructional Use of Learning Objects: On-lineVersion (2000). Disponível em: <http:// reusability.org/read/chapters/wiley.doc>. Acesso em: 21 jan. 2015.

WINCH, P. G. Diversidade linguística em livro didático de Português: alguns apontamentos. In: Caderno de Letras da UFF. Rio de Janeiro. n. 47, 2013, p. 209-221. 